\title{
QUEEN POLYMORPHISM IN AN AUSTRALIAN WEAVER ANT, POLYRHACHIS CF. DODDI
}

\author{
By J. HeINZE AND B. HöLLDOBLER
}

Theodor-Boveri-Institut, LS Verhaltensphysiologie und Soziobiologie, Am Hubland, D97074 Würzburg, F. R. Germany

\section{INTRODUCTION}

The morphological features which distinguish an ant queen from the worker caste have recently become of special interest to myrmecologists again. The discovery of wingless queens in numerous species has not only initiated a debate on how to name female reproductives with aberrant morphology (Buschinger 1987, Peeters and Crozier 1988, Loiselle and Francoeur 1989, Peeters 1991, Villet 1992), but it has also stimulated several studies on the evolutionary significance of wing reduction in ant queens (Bolton 1986, Villet 1989, Tinaut and Heinze 1992, Buschinger and Heinze 1992). Queen polymorphism, the co-occurrence of two or more morphologically distinct types of queens within a single species, is of special interest because it can give insights into the processes of morphological caste differentiation in ants. Furthermore, it is frequently correlated with dispersal polymorphism, the maintenance of which is poorly understood (e.g., Heinze 1989, Buschinger and Heinze 1992).

In the Australian weaver ant Polyrhachis (Cyrtomyrma) cf. doddi Bellas and Hölldobler (1985) discovered two different sizes of queens. We here describe the morphological characteristics of queen polymorphism in this species.

\section{Material AND Methods}

Colonies of Polyrhachis cf. doddi were collected between June and August 1980 near Port Douglas, North Queensland, Australia, and preserved in alcohol. Measurements of alitrunk length (Weber's), maximal width of alitrunk (mesonotum), and the

Manuscript received 15 March 1993. 
maximal length of the scutum in dorsal view were made at $25 \times$ magnification using a binocular microscope.

\section{RESULTS}

Variation of queen size was examined in 52 queens (including virgin female sexuals) from five colonies of $P$. cf. doddi (Fig. 1). The largest queens in this sample had an alitrunk length (Weber's) of $3.4 \mathrm{~mm}$, while the smallest measured $2.2 \mathrm{~mm}$ and thus were only little longer than the average worker $(\mathrm{n}=18,2.0 \mathrm{~mm}$, S.D. $0.1 \mathrm{~mm})$.

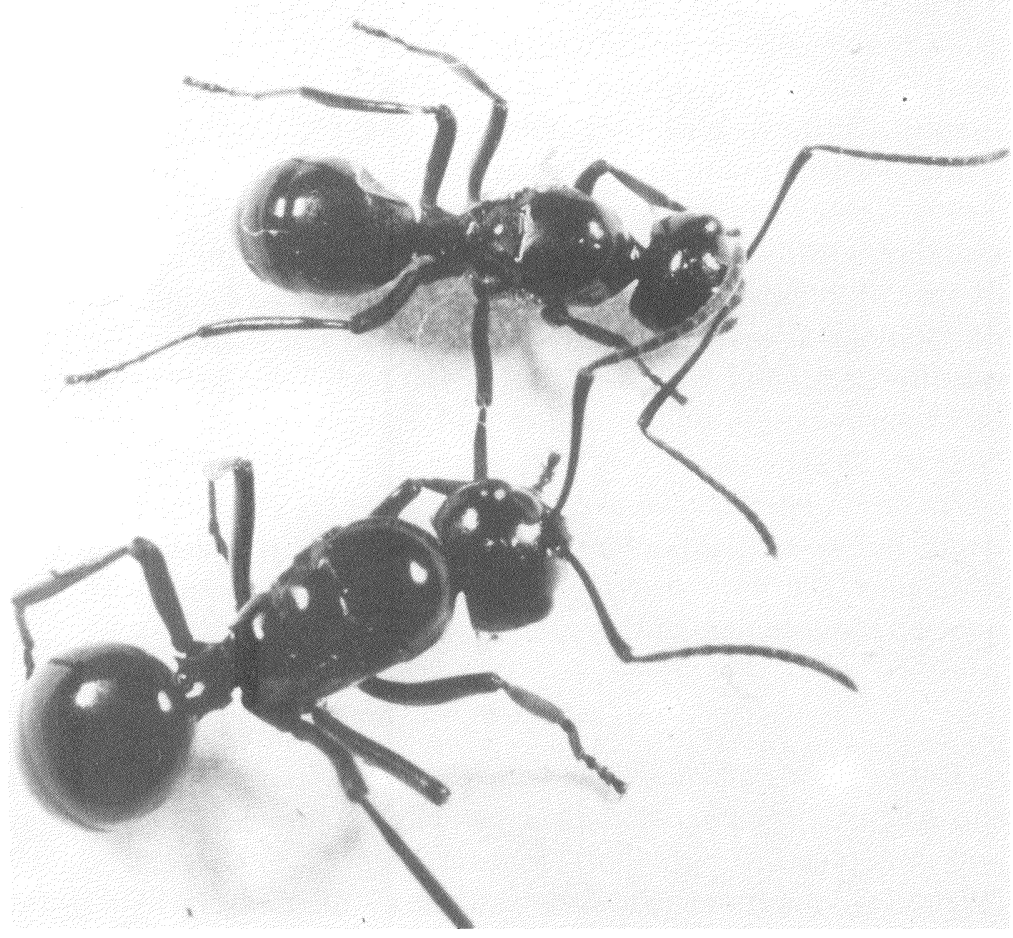

Fig. 1. A large and a small queen of the Australian weaver ant, Polyrhachis cf. doddi. 
The alitrunk width varied between $1.2 \mathrm{~mm}$ and $2.0 \mathrm{~mm}$. In comparison the mean alitrunk width of 18 workers was $1.3 \mathrm{~mm}$, S.D. $0.05 \mathrm{~mm}$.

Size distribution of queens of $P$. cf. doddi in our sample is slightly bimodal, though large and small morphs were not completely separated (Fig. 2a). The limited number of colonies available for this study, however, does not allow conclusions on the size distribution of queens in the field. In three of five examined colonies, large and small queens co-occurred. One colony contained two queens of intermediate size, and in one colony only small queens were found.

Variation in size is associated with differences in the structure of the mesonotum and wing development. In all queens, a complete set of thoracic sclerites was retained but the relative size of the mesonotum varied considerably. In some queens, the scutum strongly extended anteriorly and in dorsal view completely covered the pronotum, whereas in others it was more or less reduced (Fig. $3)$. This variation is probably best described by the ratio between scutum length and alitrunk length (index A, Tinaut and Ruano, 1992), which in $P$. cf. doddi ranged between 0.34 and 0.54. Large queens invariably had a strongly developed scutum, while in small queens relative scutum size differed widely (Fig. 2b). The polymorphism of the alitrunk is accompanied by changes in wing morphology. All examined dealate queens had wing remnants, regardless of size and structure of the mesonotum. However, large alates typically had normal, long wings, whereas the small queens had vestigial wings, resembling the rudimentary wings of irregularly occurring "winged workers" in other ant species (Wheeler 1905; Ezhikov 1934; Fig. 4) or normal wings reduced in size (Fig. 5).

Morphological variation corresponds with differences in the number of ovarioles. Approximately $86 \%$ of the large queens that were dissected proved to be inseminated, and all had fully developed active ovaries (17-22 ovarioles); only $36 \%$ of the small queens were inseminated, and $58 \%$ had fully developed ovaries (14-17 ovarioles). Worker ovaries consisted of 2 to 4 ovarioles (Bellas and Hölldobler 1985). 

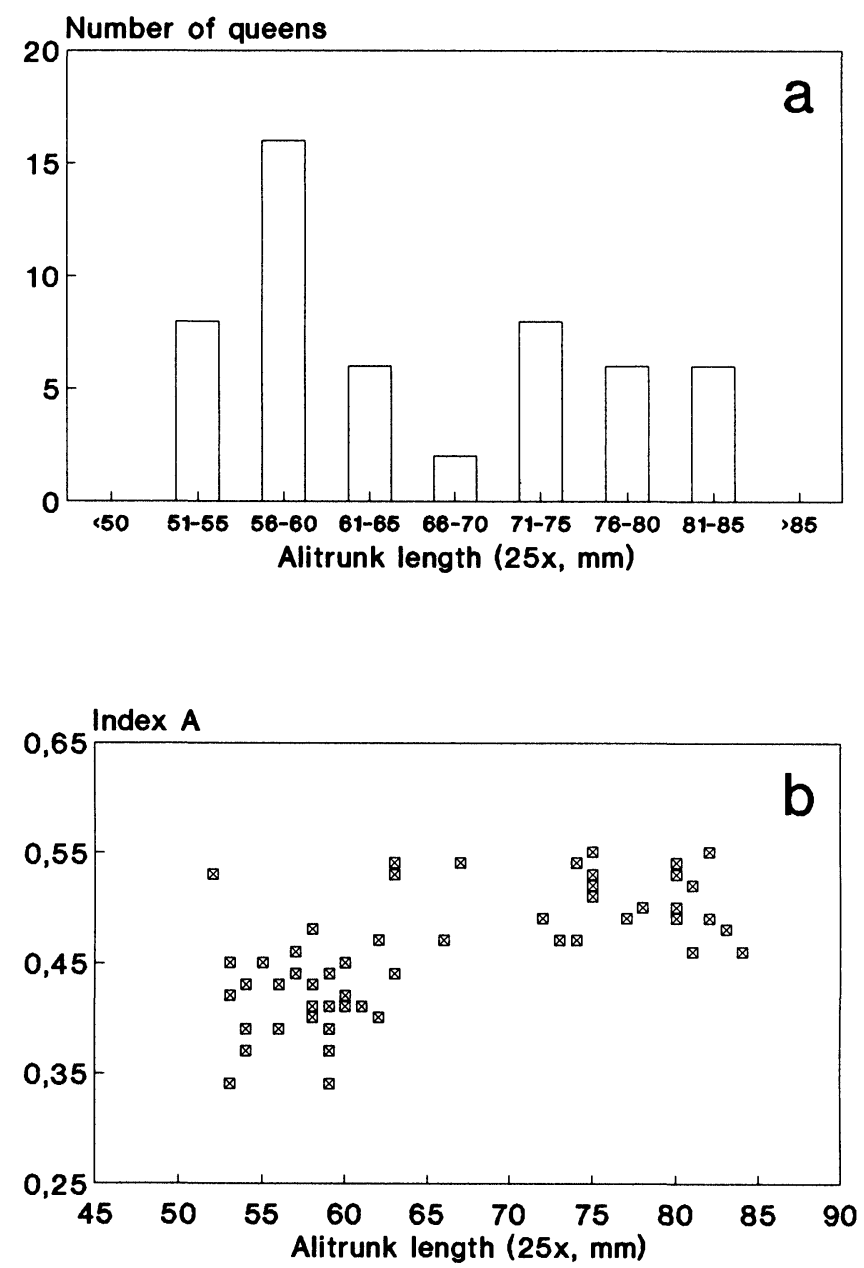

Fig. 2a. Frequency of queens found in colonies of Polyrhachis cf. doddi in correlation with alitrunk length (Weber's).

Fig. 2b. Variation of index A (the ratio of scutum length and alitrunk length, Tinaut and Ruano 1992) in correlation to alitrunk length in queens of Polyrhachis cf. doddi. 

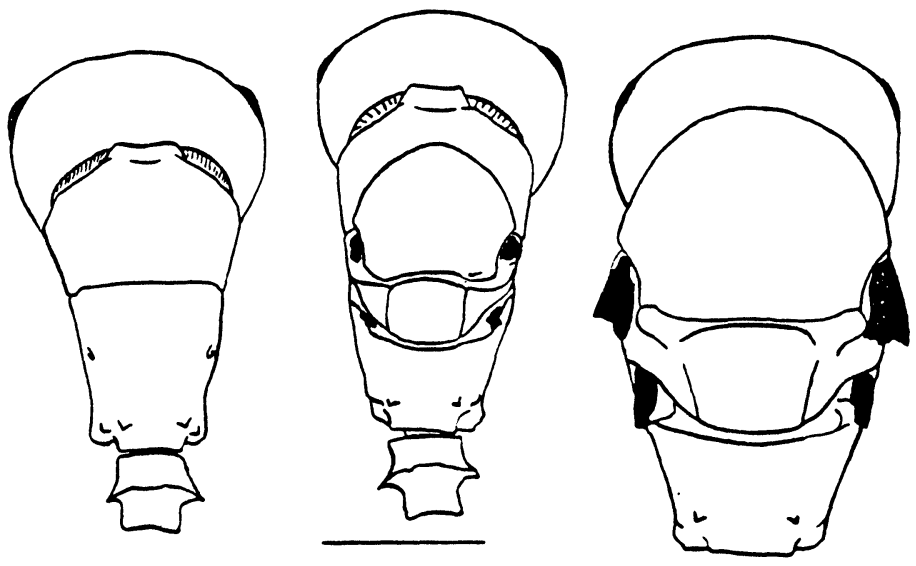

Fig. 3. Thorax, head, and petiole (only in workers and small queens) of worker, small queen, and large queen from colonies of the Australian weaver ant, Polyrhachis $\mathrm{cf}$. doddi in dorsal view. The scale equals $1 \mathrm{~cm}$.

\section{DISCUSSION}

Queens in the colonies of the Australian weaver ant, Polyrhachis cf. doddi, show a surprisingly large variability in size and morphology. In an earlier study on gland constituents in this species (Bellas and Hölldobler 1985) it was briefly speculated that small queens might belong to another species, conceivably a social parasite. However, as we show in this study, large and small queens in colonies of $P$. doddi are but the extremes of a continuous, though probably bimodal size variation. Hence we think that large and small queens do not belong to separate species but represent a peculiar case of intraspecific queen polymorphism.

In most cases of queen polymorphism described as yet, winged queens co-occur with wingless queens, whose thoracic sclerites are more or less fused (Heinze and Buschinger, 1987; Heinze et al., 1992). In other cases, such as Myrmica spp. (Elmes, 1991) or Pseudomyrmex venefica (Janzen, 1973), queen size shows a bimodal distribution without conspicuous changes in alitrunk morphology, i.e. small queens (microgynes) are isometric reductions of the larger ones. In Polyrhachis cf. doddi, all queens retain the full 


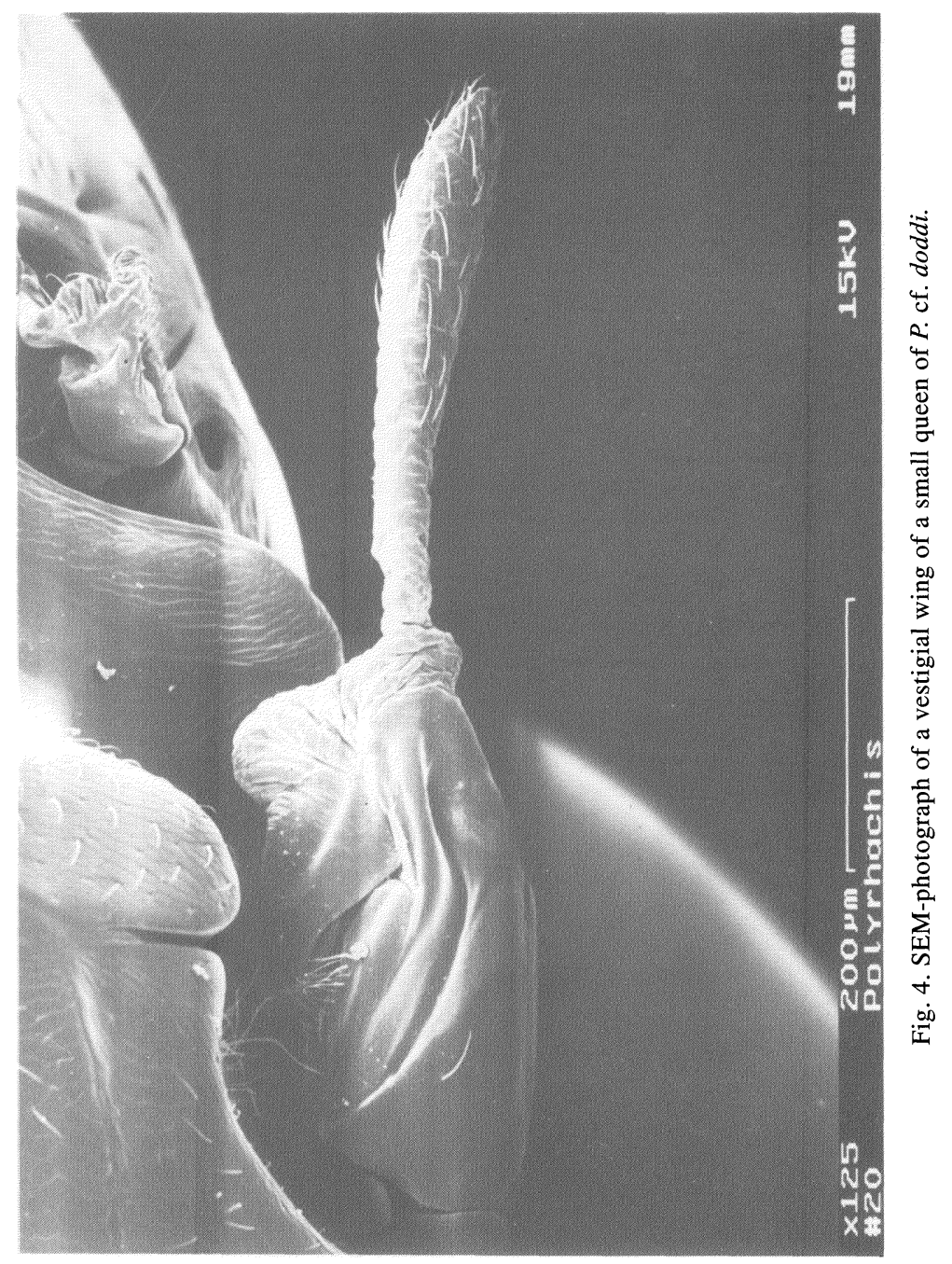




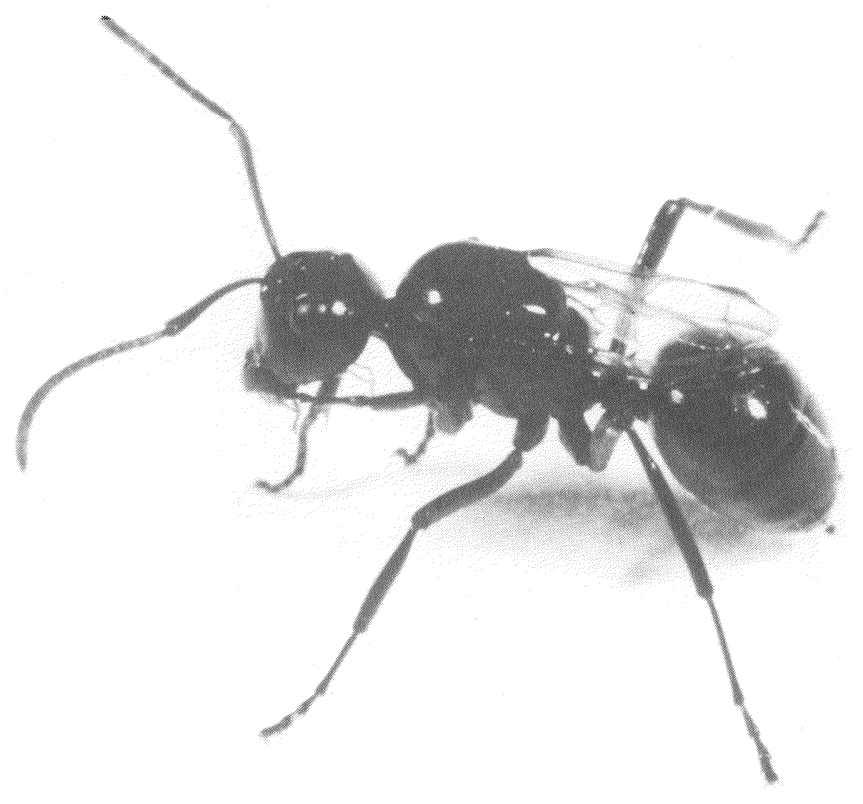

Fig. 5. Small, shortwinged queen of Polyrhachis cf. doddi.

set of thoracic sclerites and are winged; however, in small queens scutum and wings may be greatly reduced.

The development of the scutum, especially the relation of scutum length and alitrunk length, appears to be a good indicator of flight capability of winged queens. According to Tinaut and Ruano (1992), species whose queens have a large scutum, which in dorsal view fully covers the pronotum ("macronotal," Wheeler 1917), have a swarming flight, whereas in most species with less developed scutum in the queens mating occurs on the ground. Though the sexual behavior of Polyrhachis cf. doddi queens is not known, from the morphology it appears that all large queens, but also some small queens, are capable of flying, whereas the reduction of wings 
and the reduced mesonotum of many of the small queens certainly does not permit flight. The two queen morphs in $P$. cf. doddi probably follow different dispersal and colony founding strategies as was reported for several other queen-polymorphic ants (Briese, 1983; Heinze, 1989; Buschinger and Heinze, 1992). New habitat islands might thus be colonized by large, long-winged queens through solitary colony founding, whereas a single habitat patch might be fully exploited by colony fission or budding after readoption of small, short-winged queens.

As was shown by Bellas and Hölldobler (1985), both large and small queens may co-occur in single nests and both types of queens have been found to be inseminated and lay eggs. Polygyny in Polyrhachis has occasionally been reported (Yamauchi et al., 1987; Kohout, 1988; Chen Yi and Tang Jue, 1989), but appears to be absent or rare in most species.

\section{SUMMARY}

The polymorphism of queens found in colonies of the Australian weaver ant, Polyrhachis cf. doddi is described. Body size, wing length, and especially the development of the mesonotum show enormous variation. However, in all queens the full set of thoracic sclerites is retained.

\section{ACKNOWLEDGEMENTS}

B. H. is grateful to Dr. Robert Taylor and CSIRO (Division of Entomology, Canberra) for the hospitality he received in 1980. The work has in part been supported by a grant from the National Geographic Society (USA). Dr. W. Dorow, Frankfurt, gave valuable information on the occurrence of polygyny in the genus. We thank S. P. Cover and an unknown referee for helpful comments on the manuscript, especially the usage of Wheeler's terminology.

\section{REFERENCES}

Bellas, T. AND B. HöLLDOBleR

1985. Constituents of mandibular and Dufour's glands of an Australian Polyrhachis weaver ant. J. Chem. Ecol. 11: 525-538.

BOLTON, B.

1986. Apterous females and shift of dispersal strategy in the Monomorium salomonis-group (Hymenoptera: Formicidae). J. Nat. Hist. 20: 267-272. 
BRIESE, D. T.

1983. Different modes of reproductive behaviour (including a description of colony fission) in a species of Chelaner (Hymenoptera: Formicidae). Ins. Soc. 30: 308-316.

Buschinger, A.

1987. Polymorphism and reproductive division of labor in advanced ants. In: Eder, J. and Rembold, H. (eds.) Chemistry and biology of social insects. Verlag Peperny, München, 257-258.

Buschinger, A. AND J. Heinze

1992. Polymorphism of female reproductives in ants. In: Billen, J. (ed.) Biology and evolution of social insects. Leuven University Press, Leuven, 11-23.

Chen Yi AND Jue TANG

1989. Studies on colony structure and life cycle of the spined ant Polyrhachis vicina Roger. Zool. Res. 10: 57-63.

Elmes, G. W.

1991. Mating strategy and isolation between the two forms, macrogyna and microgyna, of Myrmica ruginodis (Hym. Formicidae). Ecol. Entomol. 16: $411-423$.

EzHIKov, T.

1934. Individual variability and dimorphism in social insects. Am. Nat. 67: 333-344.

HEINZE, J.

1989. Alternative dispersal strategies in a North American ant. Naturwissenschaften 76: $477-478$.

Heinze, J. And A. Buschinger

1987. Queen polymorphism in a non-parasitic Leptothorax species (Hymenoptera: Formicidae). Ins. Soc. 34: 28-43.

Heinze, J, S. P. Cover, AND B. Hölldobler

1992. Queen polymorphism in the North American harvester ant, Ephebomyrmex imberbiculus. Ins. Soc. 39: 267-273.

JANZEN, D. H.

1973. Evolution of polygynous obligate Acacia-ants in western Mexico. J. Anim. Ecol. 42: 727-750.

KoHOUT, R. J.

1988. A new species of Polyrhachis (Polyrhachis) from Papua New Guinea with a review of the New Guinean and Australian species (Hymenoptera: Formicidae: Formicinae). Mem. Qd. Mus. 25: 417-427.

Loiselle, R. AND A. Francoeur

1989. Régression du dimorphisme sexuel dans le genre Formicoxenus et polymorphisme comparé des sexes dans la famille des Formicidae (Hymenoptera). Nat. Can. 115: 367-378.

Peeters, C. P.

1991. Ergatoid queens and intercastes in ants: two distinct adult forms which look morphologically intermediate between workers and winged queens. Ins. Soc. 38: 1-15.

Peeters, C. P. AND R. H. Crozier

1988. Caste and reproduction in ants: not all mated egg-layers are "queens." Psyche 95: 283-288. 
TinAut, A. AND J. Heinze

1992. Wing reduction in ant queens from arid habitats. Naturwissenschaften 79: 84-85.

Tinaut, A. AND F. RuANo

(1992) Braquipterismo y apterismo en formicidos. Morfologia y biometria en las hembras de especies ibericas de vida libre (Hymenoptera: Formicidae). Graellsia 48: 121-131.

VILLET, M. H.

1989. A syndrome leading to ergatoid queens in ponerine ants (Hymenoptera: Formicidae). J. Nat. Hist. 23: 825-832.

1992. Definitions of "caste" in social insects. Ethol. Ecol. Evol. 4: 213-224.

WHEELER, W. M.

1905. Worker ants with vestiges of wings. Bull. Am. Mus. Nat. Hist. 21: 408.

1917. The phylogenetic development of subapterous and apterous castes in the Formicidae. Proc. Nat. Acad. Sci. 3: 109-117.

Yamauchi, K., Y. Ito, K. Kinomura and H. TaKamine

1987. Polycalic colonies of the weaver ant Polyrhachis dives. Kontyû 55: 410-420. 

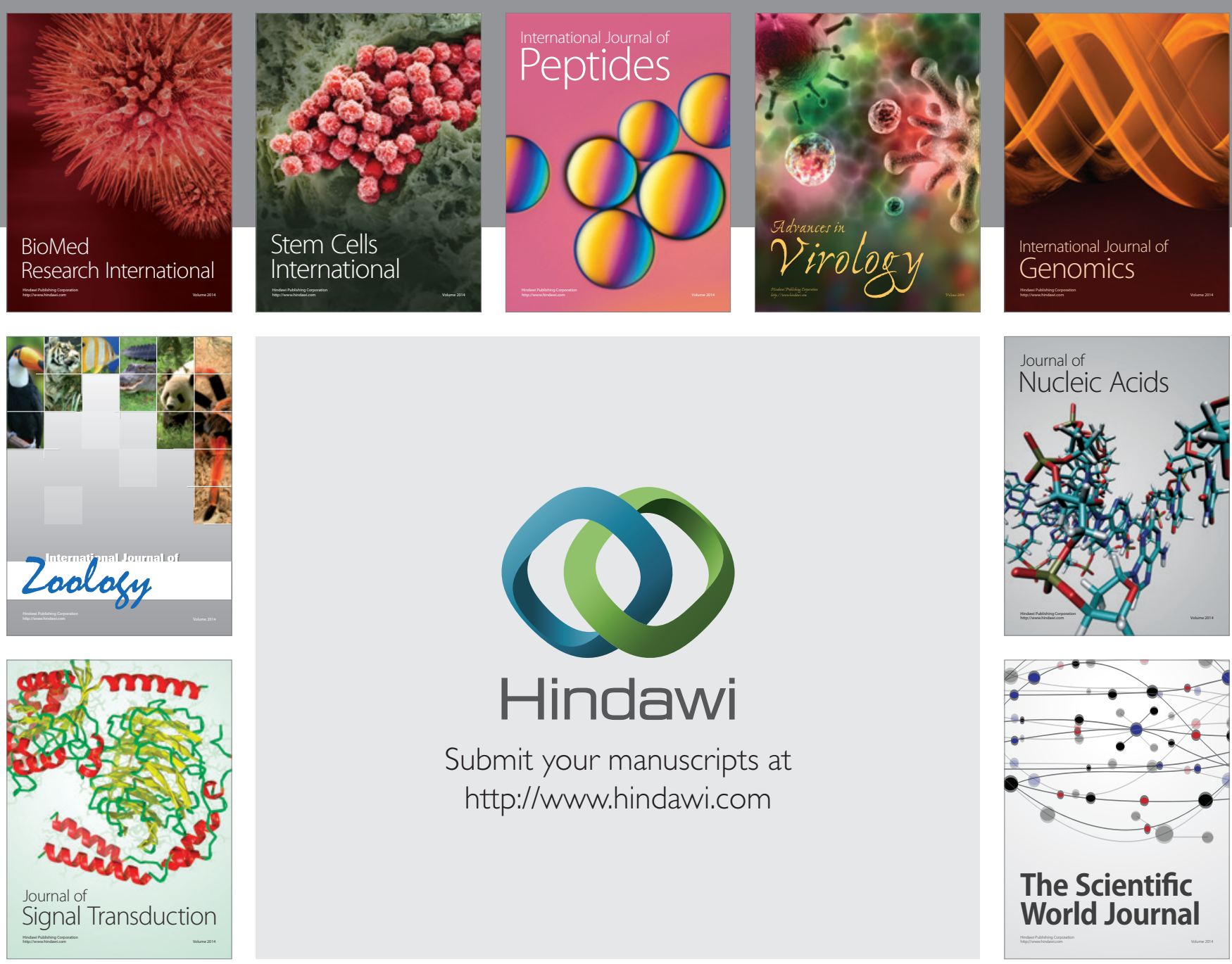

Submit your manuscripts at

http://www.hindawi.com
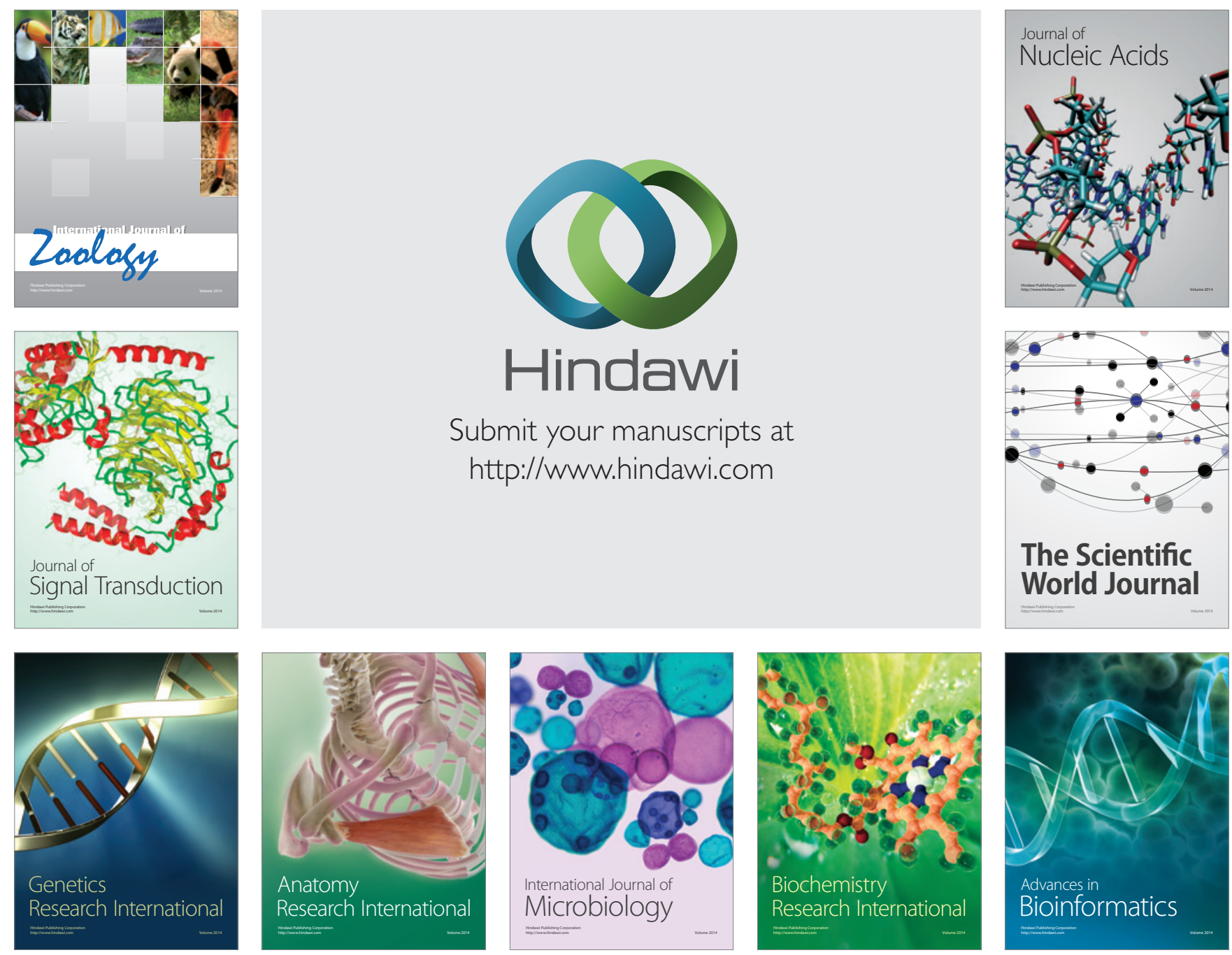

The Scientific World Journal
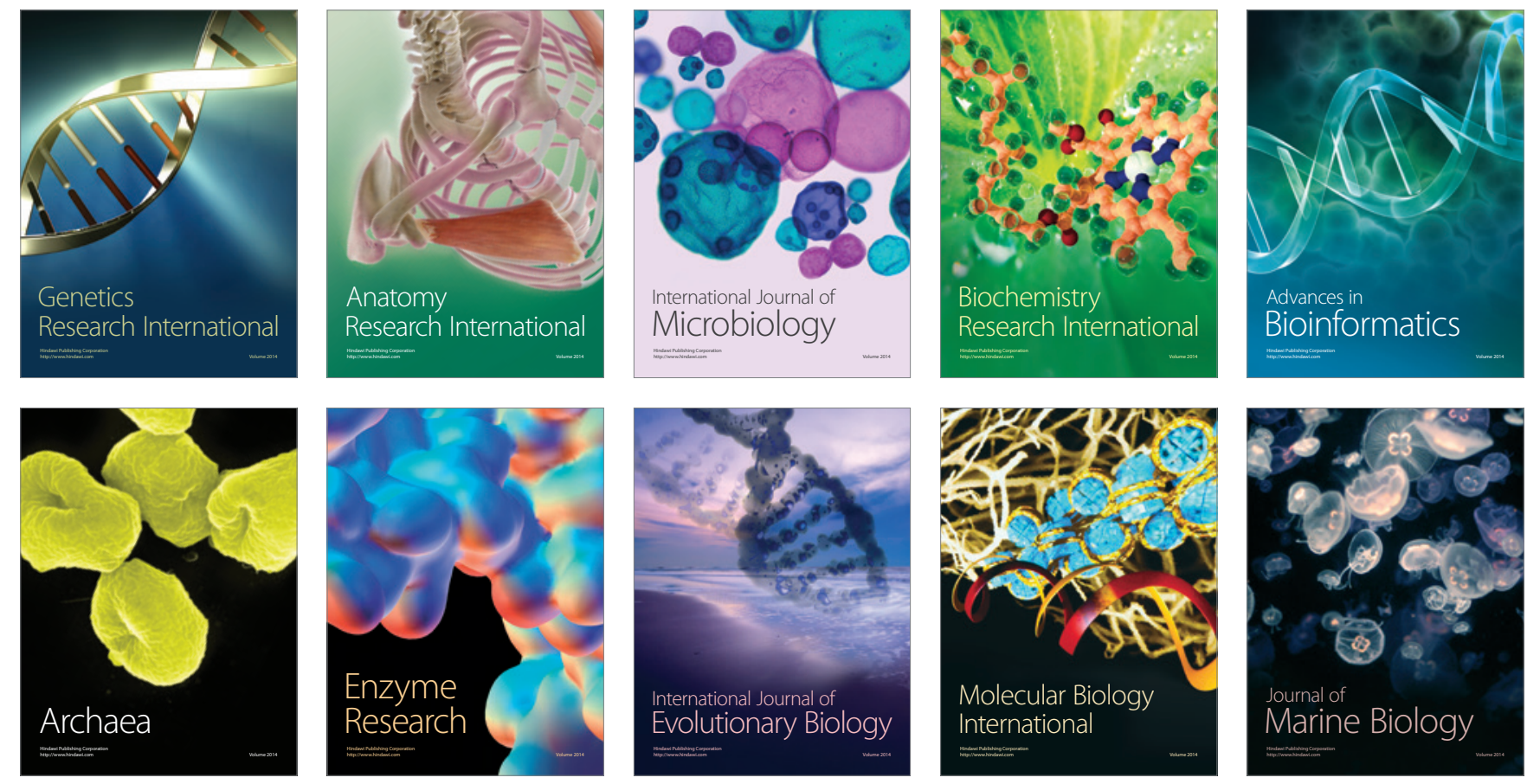